\title{
Trabalhadores de Pikine
}

\author{
CRISTIANO SOBROZA MONTEIRO \\ Universidade Estadual de Campinas | Campinas, SP Brasil \\ cristianosobroza@gmail.com \\ DOI 10.11606/issn.2316-9133.v30i1pe179356
}

Este ensaio busca retratar a constituição do ethos para trabalho e a circulação de mercadorias entre trabalhadores de rua de Pikine, um departamento da região de Dakar, no Senegal. Constituído de dez fotografias, oito delas, focalizando fragmentos da trajetória de um trabalhador, bem como a manufatura específica comercializada, o ensaio propõe, também, uma reflexão sobre a relação entre corporalidade, trabalho e cultura material no contexto da venda de rua naquele país. As mercadorias, comercializadas por esses trabalhadores, elucidam as formas de agenciamento da cultura material local, as suas estratégias de venda e a maneira como os senegaleses consomem cotidianamente.

O ensaio foi produzido durante pesquisa etnográfica, realizada nos meses de agosto e setembro de 2019, em Dakar, e se insere em um debate mais amplo, relacionado à minha pesquisa de doutoramento intitulada: “O que cabe na mala?”: deslocamentos e circulação de objetos da diáspora senegalesa em "terra de italianos", que busca reconhecer os modos pelos quais os senegaleses que vivem na cidade de Caxias do Sul-RS, se conectam, através dos objetos, a diferentes tempos e espaços na atual conjuntura do capitalismo global, passando a constituir, dessa maneira, redes transnacionais de imigração, nas quais fluem pessoas, capitais, sentidos e matéria..

\section{sobre o autor}

\section{Cristiano Sobroza Monteiro}

Doutorando em Antropologia Social pela Universidade

Estadual de Campinas, com graduação e mestrado em Ciências Sociais pela Universidade Federal de Santa Maria.

Contribuição de Autoria: Não se Aplica

Financiamento: A pesquisa foi financiada com recursos da

Fundação de Amparo à pesquisa do Estado de São Paulo

(Processo n 2017/03724-0)

Recebido em 09/12/2020

Aceito para publicação em 08/06/2021 


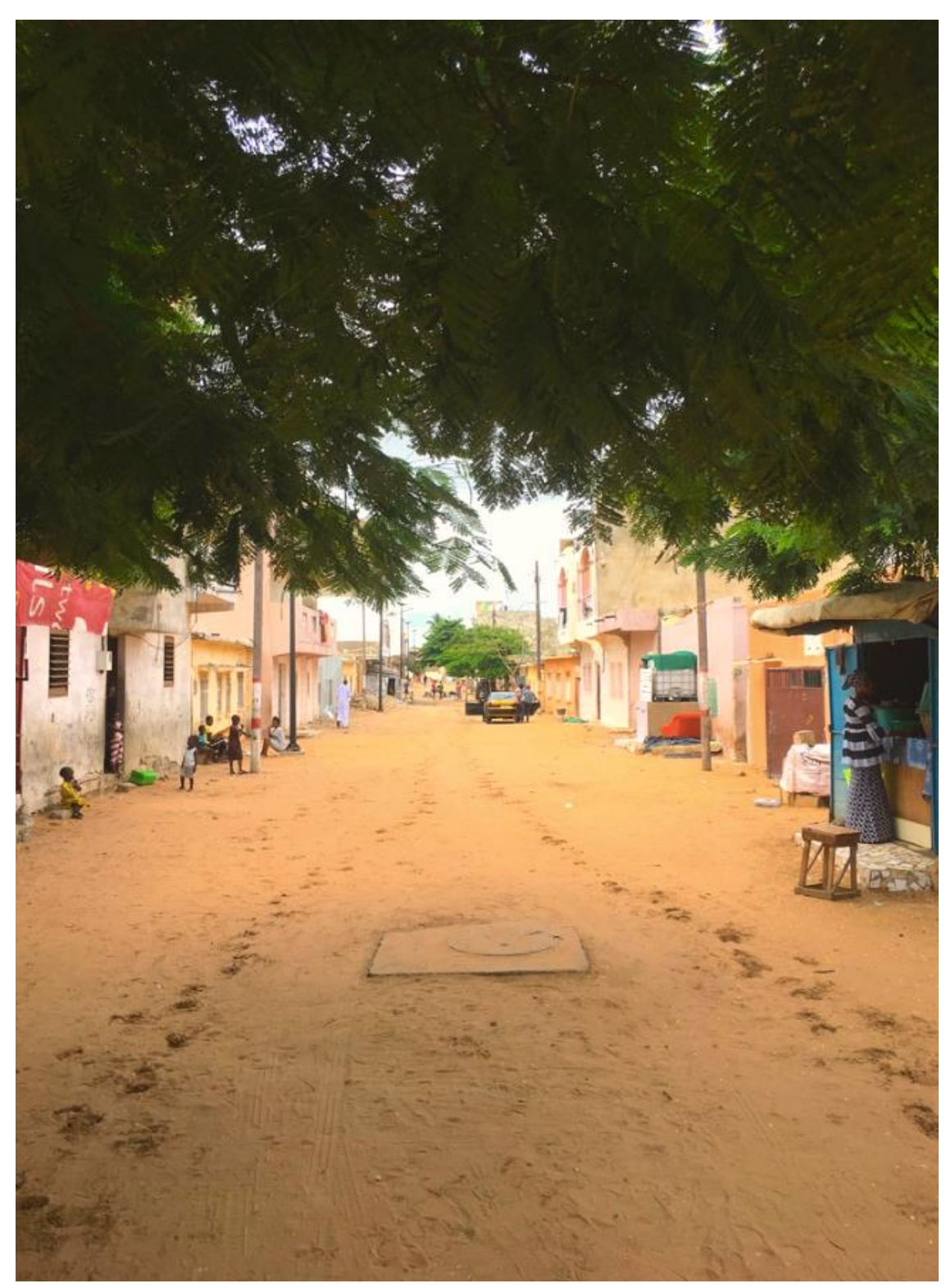

Fotografia 1. O cotidiano de Pikine é constituído pelo vai e vem de centenas de trabalhadores de rua, chamados localmente de boutikou mbagg (wolof) ou marchand ambulant (francês), que ofertam aos moradores do lugar, diversos tipos de mercadorias. Na língua wolof, "boutikou" significa "loja" e "mbagg" significa "ombro". A expressão designa a ideia de "levar a loja nos ombros". Esses trabalhadores, costumam comercializar os seus produtos de duas maneiras: expondo-os, em pequenas tendas, próximo às suas moradias, ou, deslocando-se junto a elas, por entre as ruas e vielas do departamento. Dakar, 2019. 


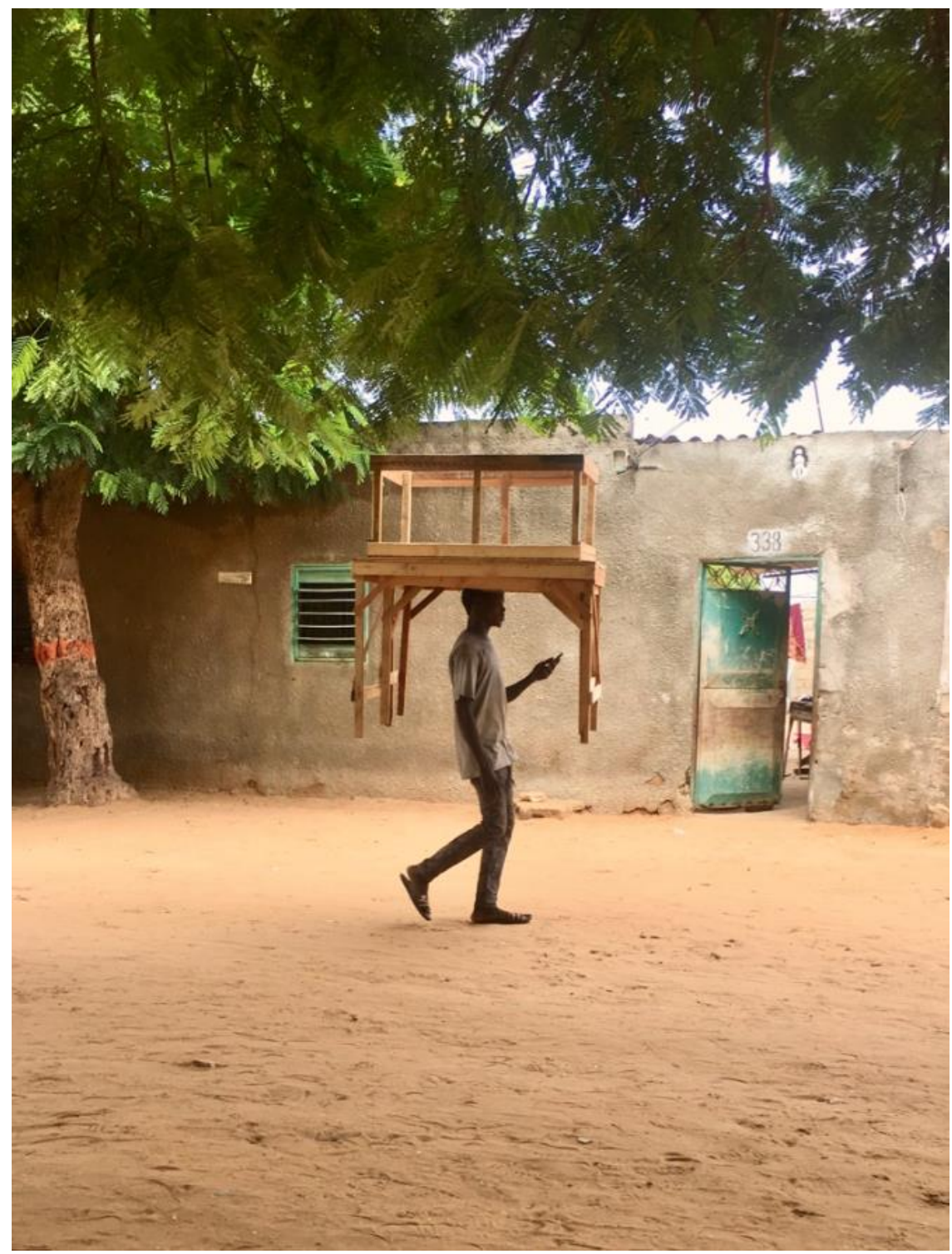

Fotografia 2. Os comerciantes que carregam as mercadorias junto ao corpo, geralmente, alocam-nas sobre a própria cabeça, percorrendo a frente das casas, à espera do aceno de algum possível comprador. Dakar, 2019. 


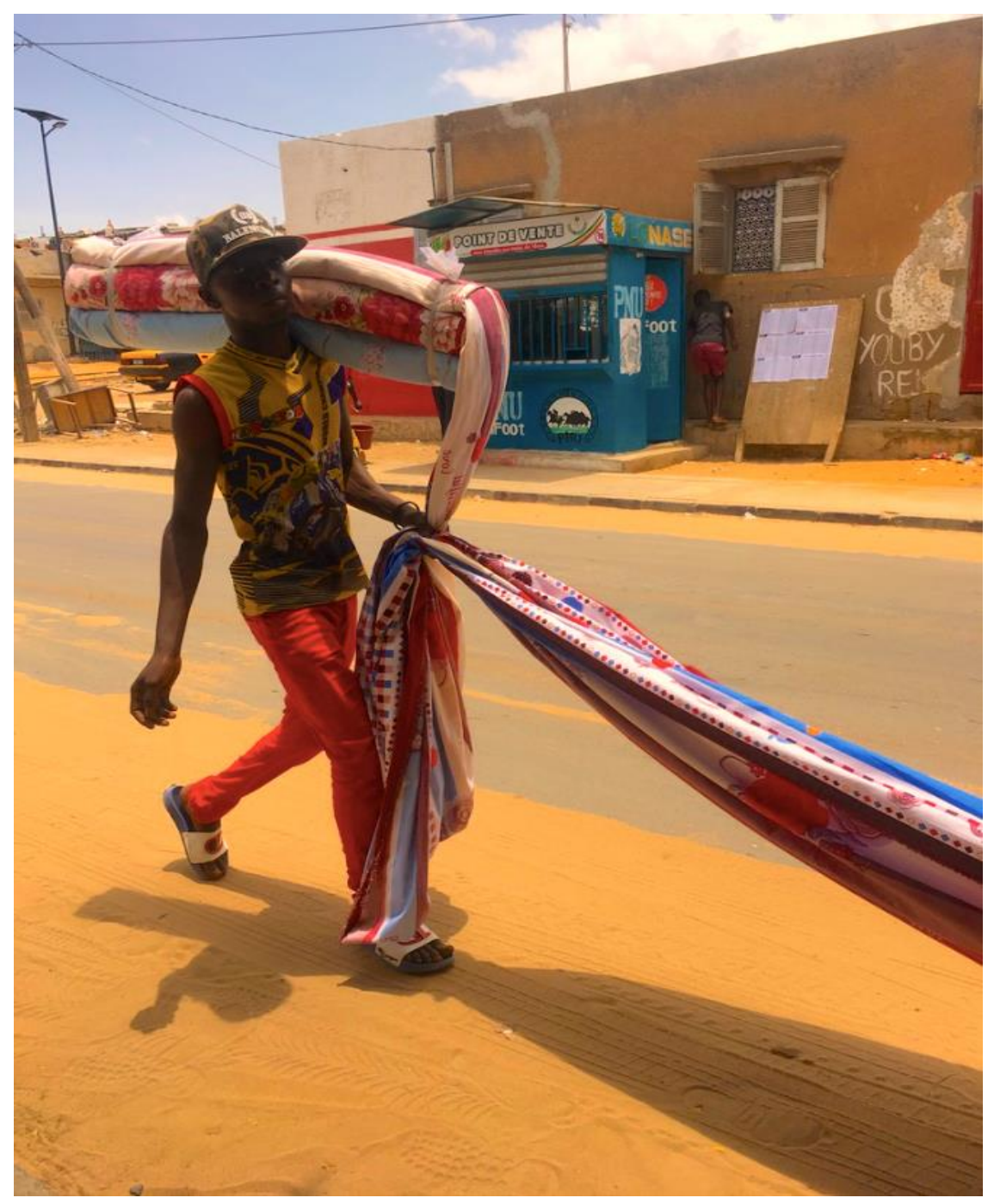

Fotografia 3. Mamadou é um comerciante de tecidos. Juntamente com um amigo, percorrem, todos os dias, longas distâncias no departamento, segurando, cada um deles, uma ponta do tecido. Manejar o tecido dessa maneira, explicou o vendedor, permite despertar, no cliente, um desejo mais acentuado de compra, já que a estamparia, por estar exposta, pode ser efetivamente contemplada. Dakar, 2019. 


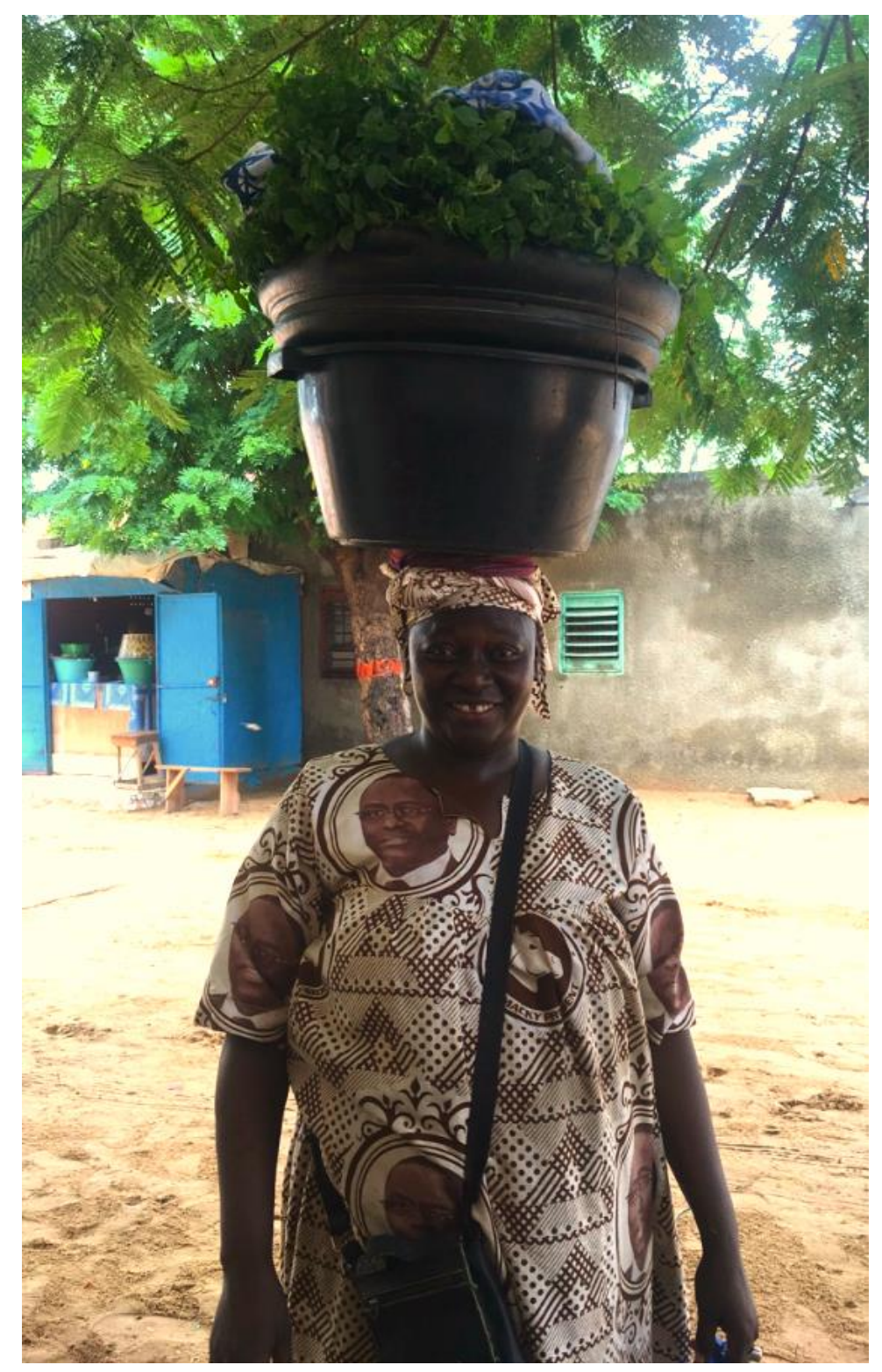

Fotografia 4. Nos fundos de casa, Mère Nana cultiva diversos tipos de legumes e hortaliças. Três vezes por semana, Mère Nana carrega o seu bol (bacia) com as verduras, e dirige-se a Pikine para comercializá-las. De porta em porta, ela vai oferecendo aos moradores, hortaliças e legumes frescos. Com os ganhos da venda, contribui com a manutenção das despesas da casa e no sustento dos filhos. Dakar, 2019. 


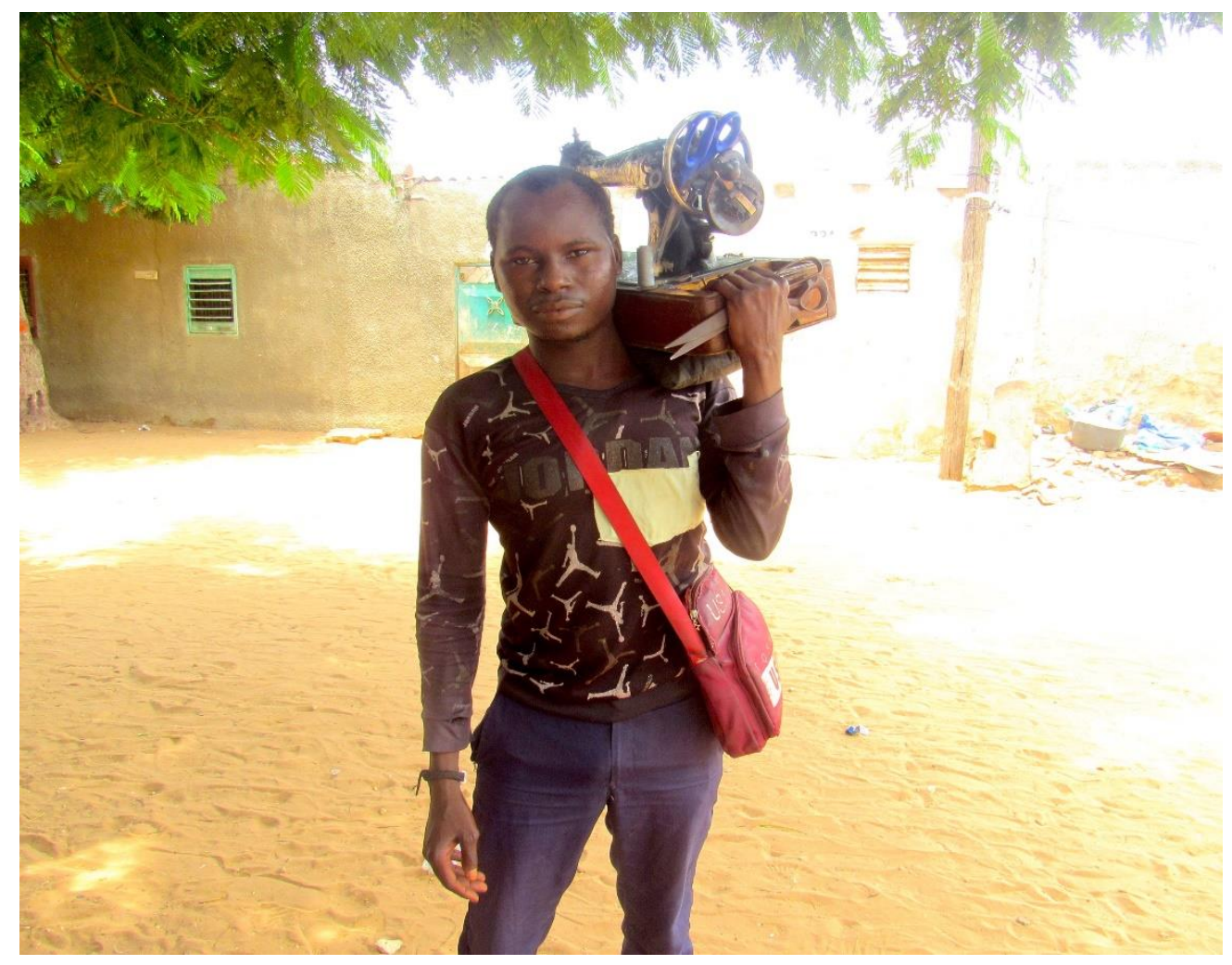

Fotografia 5. Aliko é um tailleur (costureiro) nigeriano. Sua especialidade constitui-se em realizar pequenos consertos de roupas na própria residência dos moradores de Pikine. Provido de uma máquina de costura, alçada sobre os próprios ombros, Aliko utiliza-se de uma estratégia de comercialização bastante interessante: enquanto desloca-se pelas ruas do departamento, ele vai estalando, com força, as suas tesouras, que emitem estalos que podem ser ouvidos à distância pelos moradores. Aliko contou que essa é uma maneira de atrair a atenção dos clientes, caso eles necessitem realizar algum reparo em uma peça de roupa. Dakar, 2019. 


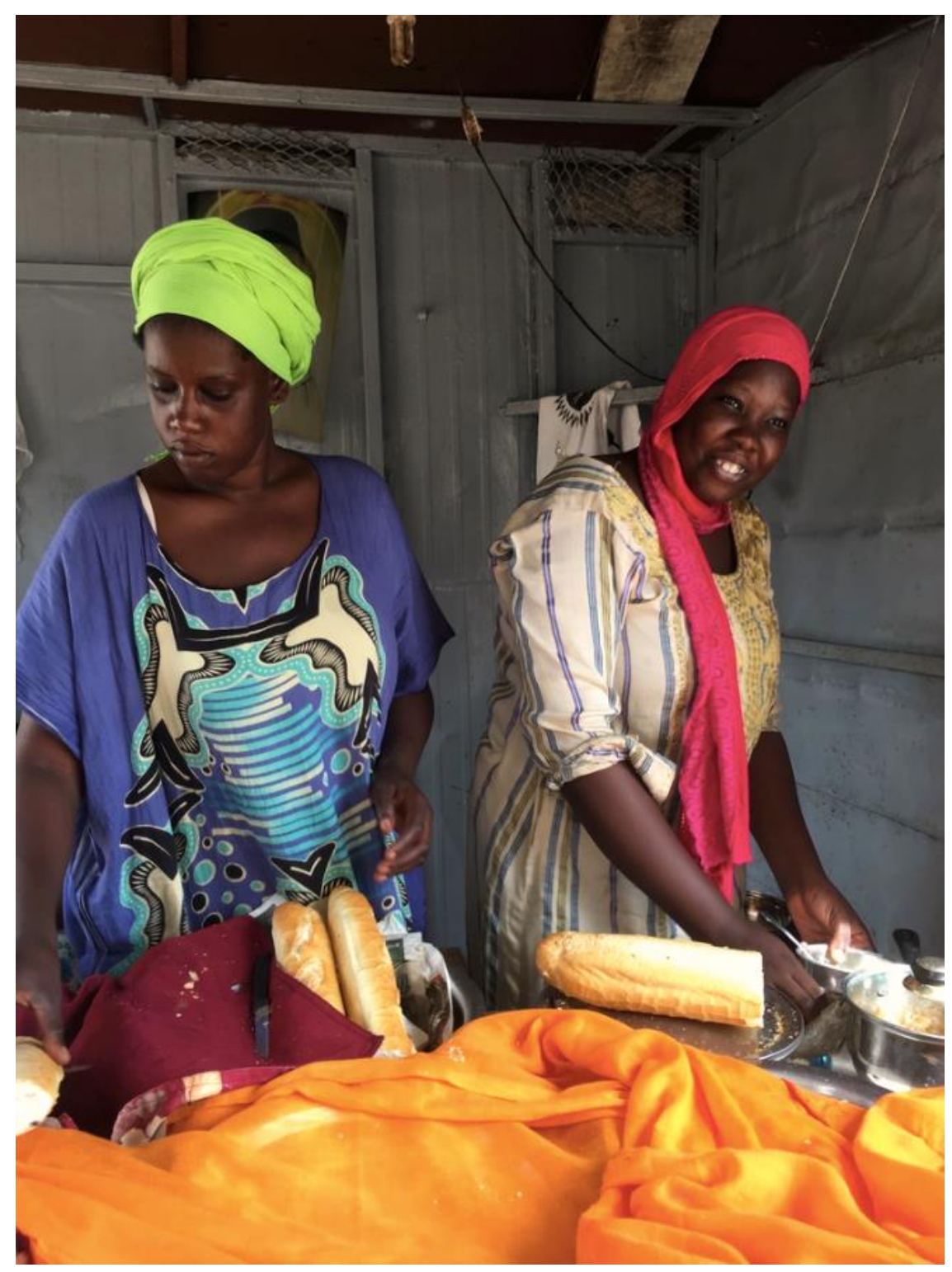

Fotografia 6. Kapsa e a filha Aisata possuem, ao lado de casa, uma pequena tenda, na qual comercializam thon, uma pasta (mistura de peixe com maionese), muito consumida pelos senegaleses, especialmente, no café da manhã. Todas as manhãs, os diversos moradores das redondezas, conduzem-se até a tenda de Kapsa e Aisata, com seus baguetes (pão) em mãos, para recheá-las com o thon produzido por elas. Dakar, 2019. 


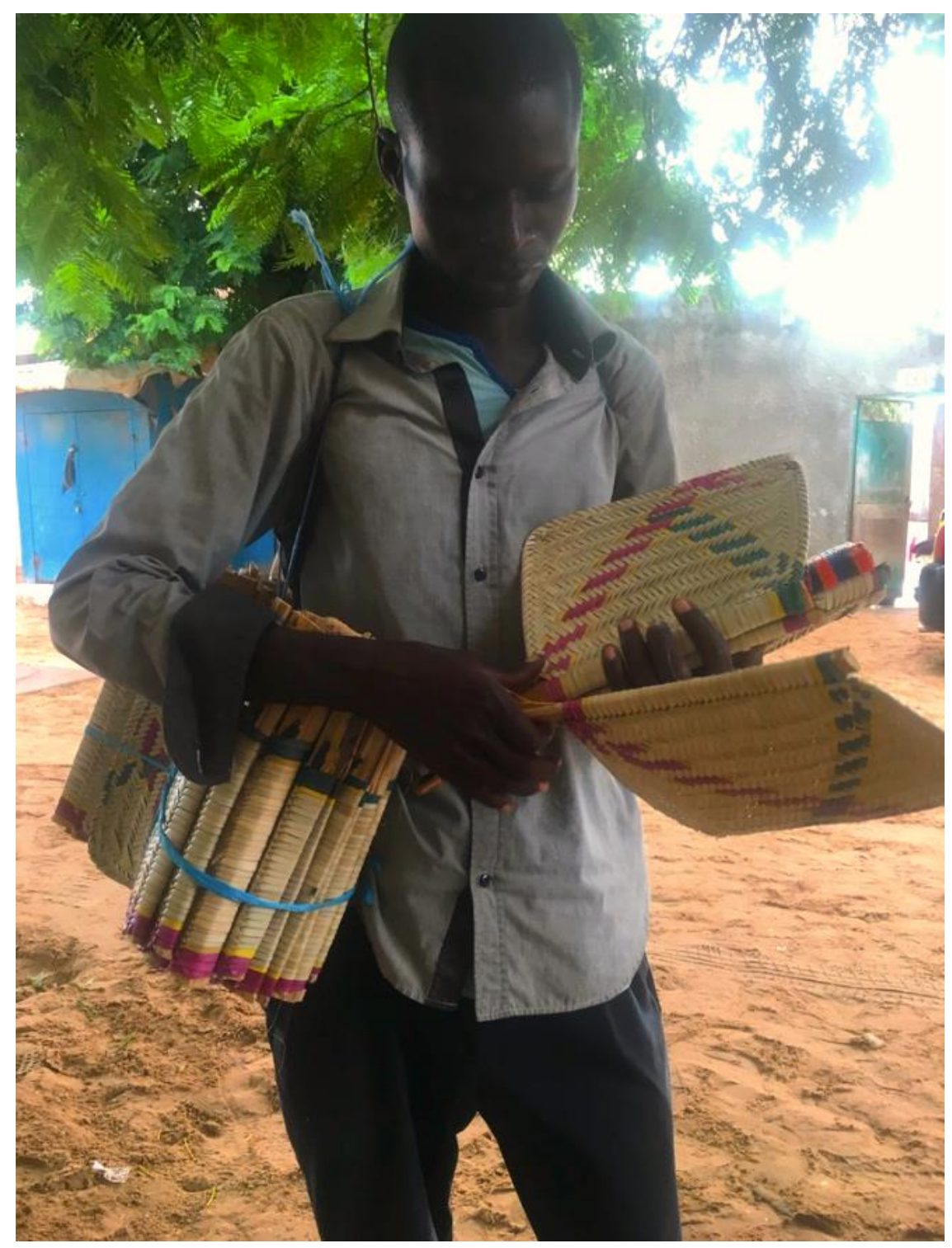

Fotografia 7. Wantaye, é um dos objetos (adereços) mais tradicionais da cultura senegalesa. Trata-se de uma espécie de abanador, feito a partir do trançado da palha e sustentado por uma haste de madeira, muito utilizado pelos senegaleses, para afugentar os insetos e o calor. Quando criança Abdou aprendeu a confeccionar o wantaye com a mãe. O ensinamento, tornou-se um negócio, já que é através da comercialização dessas peças, sobretudo, nos dias de maior calor, que Abdou obtém o seu sustento e o da família. Dakar, 2019. 


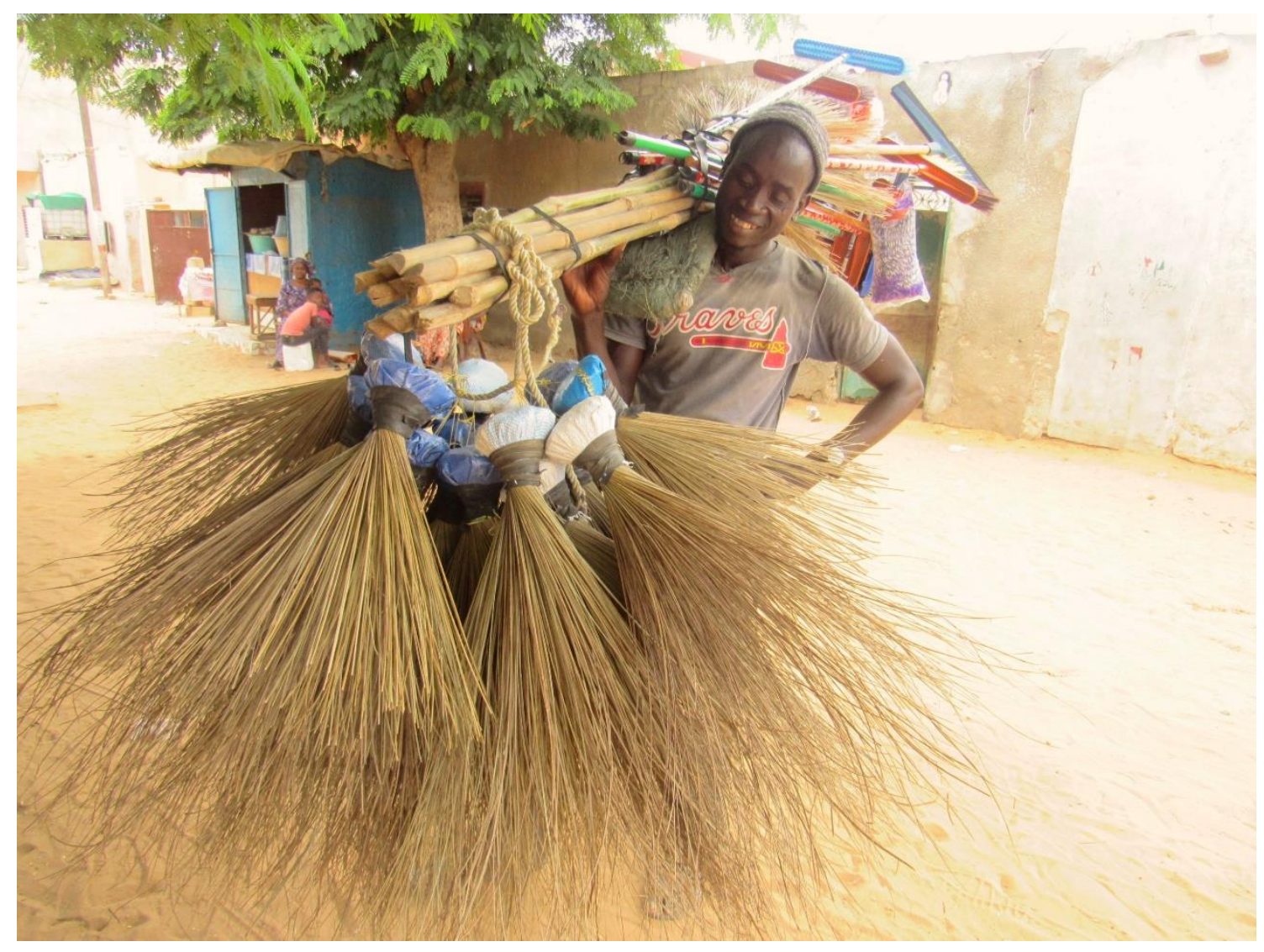

Fotografia 8. Cher é um comerciante de vassouras. Atravessadas sobre o ombro, em sua frente, Cher transporta as vassouras que denomina de tradicionais, feitas de palha com uma pequena base envolvida por uma borracha preta. Já em suas costas, estão alocadas as vassouras que ele chama de modernas, feitas de plástico, e de variadas cores e modelos. É um velho amigo de Cher quem produz as vassouras tradicionais, cabendo a ele, comercializá-las pelas ruas de Pikine. Dakar, 2019. 


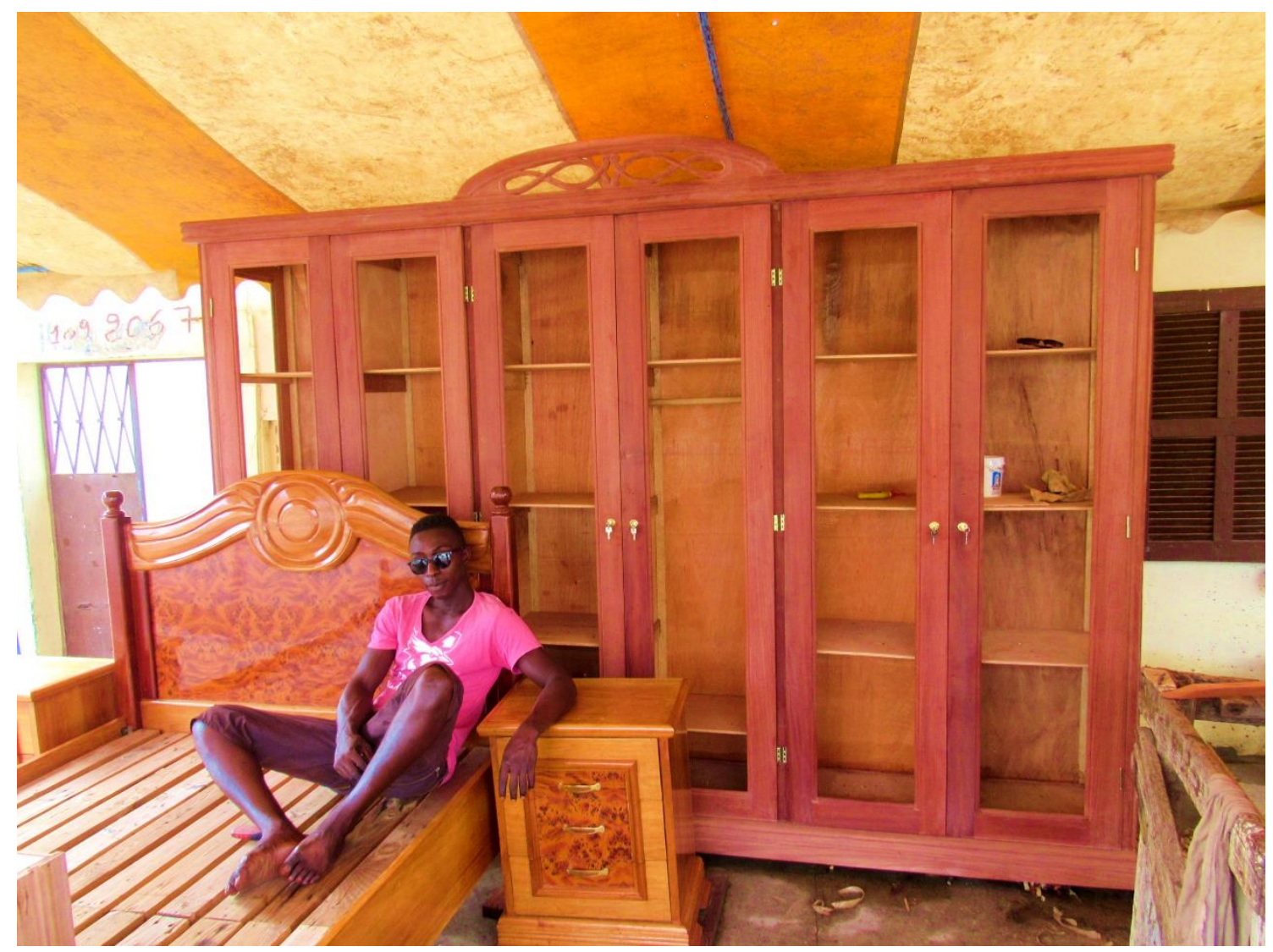

Fotografia 9. As ruas de Pikine são repletas de itens moveleiros expostos nas calçadas e que são produzidos em marcenarias à céu aberto. Ansoumane é um menuisier (marceneiro), que exibe, com orgulho, a cama e o guarda-roupas recém finalizados e aguardando por algum comprador. Dakar, 2019. 


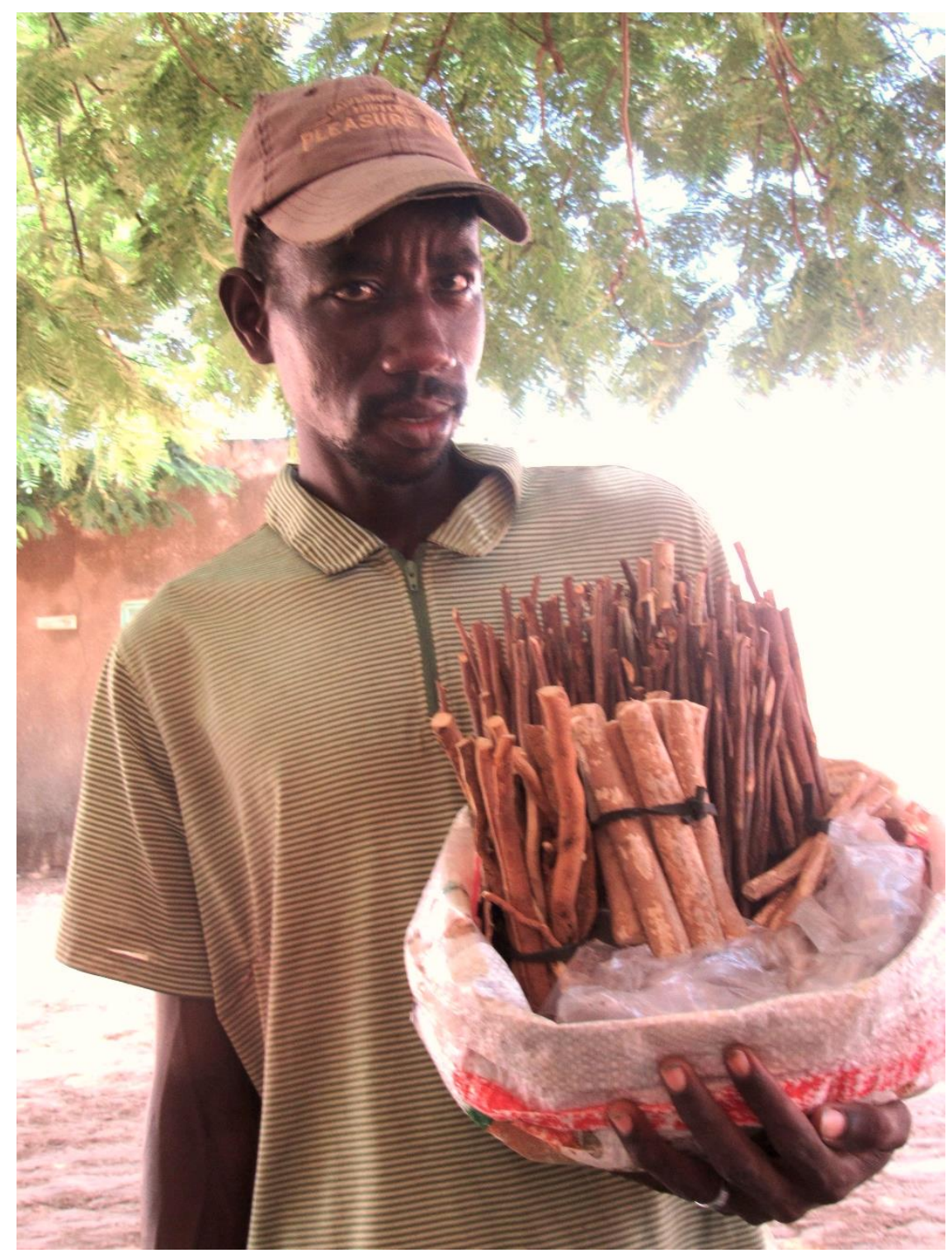

Fotografia 10. Moustapha é um comerciante de shotiou, uma haste de madeira, popularmente conhecida, como escova de dentes tradicional. O shotiou é feito a partir da poda de algumas espécies de árvores locais. O uso regular, relatou o vendedor, ajuda a combater a placa dentária, a cárie, além de embranquecer os dentes e combater o mau hálito. Entretanto, segundo Moustapha, as suas propriedades vão além da proteção da saúde dos dentes, servindo, também, como um amuleto de sorte, que protege espiritualmente o usuário, contra o mau-olhado e as más línguas. Dakar, 2019. 